\title{
Kvasci za proizvodnju bioetanola iz hidrolizata lignoceluloznih sirovina
}

\section{Sažetak}

Velika količina lignoceluloznog otpada, kojeg čine uglavnom celuloza, hemiceluloza i lignin, nastaje u šumarstvu, poljoprivredi i prehrambenoj industriji. Obzirom na dostupne količine ovih jeftinih i obnovljivih sirovina u Republici Hrvatskoj, važno je razmotriti mogućnosti njihove primjene u proizvodnji bioetanola $i$ raznih drugih biotehnoloških proizvoda. Lignocelulozni hidrolizati su složene smjese heksoza i pentoza te drugih spojeva od kojih neki mogu djelovati kao inhibitori fermentacije. U ovom radu dan je pregled kvasaca koji se koriste i/ili istražuju za proizvodnju etanola iz lignoceluloznih hidrolizata.

Ključne riječi: bioetanol, lignoceluloza, kvasci, heksoze, pentoze, inhibitori

\section{Uvod}

Lignocelulozni materijali su glavna komponenta biljne biomase i predstavljaju obnovljivi izvor energije dostupan na Zemlji (Salvachua i sur., 2011). Riječ je o različitim poljoprivrednim ostacima (npr. ostaci nakon berbe pšenice, repe i kukuruza, pulpa šećerne repe, sijeno, zelena i suha trava) i ostacima drvne industrije (npr. piljevina, strugotine i ostali ostaci drva; Sun i Cheng, 2002). Strukturni polimeri lignoceluloznih materijala su celuloza, hemiceluloza i lignin, a njihovi udjeli ovise o vrsti biljke. Općenito lignoceluloza sadrži 25-50 \% celuloze, 20-40 \% hemiceluloze i 10-35\% lignina (Sluiter i sur., 2010; loelovich, 2014). U literaturi su dobro opisane vrlo složena struktura lignoceluloze te kemijske strukture celuloze, hemiceluloze i lignina (Alonso Bocchini Martins i sur., 2011; Hilgert i sur., 2013; Anwar i sur., 2014 i lsikgor i Becer, 2015).

Većina ugljikohidrata lignoceluloze može se hidrolizom razgraditi do jednostavnih šećera te potom prevesti u brojne biotehnološke proizvode (Alriksson, 2006; Janušić i sur., 2008; Taherzadeh i Karimi, 2007; Taherzadeh i Karimi, 2008; Kumar i sur., 2009). Bioetanol je od izuzetne važnosti jer se koristi kao biogorivo (Srivastava $i$ sur., 2015). Prednost bioetanola u odnosu na klasična fosilna goriva je u smanjenju emisije tvari štetnih za zdravlje i okoliš, što je važno na lokalnoj i globalnoj razini (Chlopek, 2007). Obzirom na lignocelulozni otpad dostupan u velikim količinama u Republici Hrvatskoj, to bi mogao postati stabilan izvor obnovljivih sirovina i dobar temelj razvoja proizvodnje bioetanola, ali i drugih proizvoda dodane vijednosti.

Lignocelulozni materijali su teško razgradivi zbog kristalične strukture celuloze i kompleksne strukturne organizacije celuloze, hemiceluloze i lignina. Stoga je prije samog biotehnološkog procesa, ovisno o vrsti lignoceluloznog materijala i željenom proizvodu, potrebno provesti odgovarajuće postupke predobrade (fizikalne, fizikalno-kemijske, kemijske ili biološke). Najvažnije karakteristike različitih metoda predobrade lignoceluloze

Izv. prof. dr. sc. Vlatka Petravić Tominac i prof. dr. sc. Božidar Šantek, Laboratorij za biokemijsko inženjerstvo, industrijsku mikrobiologiju i tehnologiju slada i piva, Zavod za biokemijsko inženjerstvo, Prehrambeno-biotehnološki fakultet, Sveučilište u Zagrebu, Pierottijeva 6, Zagreb, Hrvatska, tel.+38514605056, e-mail:vpetrav@pbf.hr

Martina Tolvajčcić, sveučilišna prvostupnica inženjerka biotehnologije i studentica diplomskog studija Upravljanje sigurnošću hrane,

Prehrambeno-biotehnološki fakultet, Sveučilište u Zagrebu, Pierottijeva 6, Zagreb, Hrvatska

Izv. prof. dr. sc. Damir Stanzer i izv. prof. dr. sc. Jasna Mrvčić, Laboratorij za tehnologiju vrenja i kvasca,

Zavod za prehrambeno-tehnološko inženjerstvo, Prehrambeno-biotehnološki fakultet, Sveučilište u Zagrebu, Pierottijeva 6, Zagreb, Hrvatska 
opisane su u više preglednih radova, od kojih su neki općeniti, dok su neki usmjereni upravo na predobradu u procesima proizvodnje bioetanola (Pérez i sur., 2002; Mosier i sur., 2005; Janušić i sur., 2008; Taherzadeh i Karimi, 2008; Kumar i sur., 2009a; Mussato i Teixeira, 2010; Zhang i Shahbazi, 2011; Chiaramonti i sur., 2012; Mood i sur., 2013; Putro i sur., 2016; Chen i sur., 2017; Kumar i Sharma, 2017).

Postoji nekoliko mogućnosti za provođenje hidrolize lignoceluloznih sirovina, a najčešće se primjenjuju kemijska i enzimska hidroliza (Taherzadeh i Karimi, 2007). Slika 1 prikazuje primjer hidrolize i kasnije fermentacije u proizvodnji bioetanola. Hidrolizom celuloze oslobađa se glukoza, a hidrolizom hemiceluloze oslobađaju se heksoze (glukoza, manoza, galaktoza) i pentoze (ksiloza, ramnoza, arabinoza). Oslobođeni šećeri se mogu prevesti u etanol, a lignin zaostaje kao sekundarni produkt.

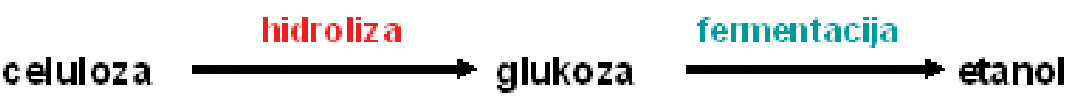

hemiceluloza

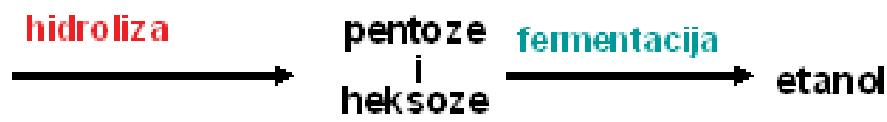

Slika 1. Konverzija lignoceluloze u fermentabilne šećere, a potom u etanol (Taherzadeh i Karimi, 2007).

Figure 1. Conversion of lignocellulose to fermentable sugars, and then in ethanol (Taherzadeh and Karimi, 2007)

Osim šećera, kiselinskom hidrolizom lignoceluloznih materijala nastaje i veći broj nusprodukata razgradnje složenih ugljikohidrata i lignina, koji su toksični za radne mikroorganizme i negativno utječu na efikasnost fermentacije (Mussatto i Roberto, 2003). Ovi inhibitori obično se na temelju porijekla dijele u tri velike skupine, a to su organske kiseline, derivati furana i fenolni spojevi. Nastajanje inhibitora ovisi o samoj sirovini, ali i o metodi hidrolize te uvjetima pri kojima se ona provodi (Palmqvist i Hahn-Hägerdal, 2000a,b). Među velikim brojem inhibitora posebno se može izdvojiti njih nekoliko, a to su furfural, vanilin, octena kiselina, mravlja kiselina i 5-hidroksimetil furfural. Mehanizmi nastajanja inhibitora, njihovo djelovanje i načini prevladavanja problema inhibicije u lignoceluloznim hidrolizatima opisani su u literaturi (Alriksson, 2006; Palmqvist i Hahn-Hägerdal, 2000a,b).

\section{Općenito o mikroorganizmima za proizvodnju bioetanola iz lignoceluloznih hidrolizata}

Zbog ranije navedenih činjenica je izuzetno važno odabrati odgovarajuće mikroorganizme koji mogu učinkovito fermentirati šećere prisutne u lignoceluloznim hidrolizatima, a istodobno su dovoljno otporni na prisutne inhibitore. Optimalni radni mikroorganizam trebao bi posjedovati niz osobina, a njih može imati mikroorganizam izoliran iz prirode ili se mogu dobiti primjenom genetičkog inženjerstva. Za primjenu na lignoceluloznim sirovinama istražuju se razni radni mikroorganizmi - prokariotski i eukariotski (Weber i sur., 2010). 
Korištenje jeftine hranjive podloge je jedan od kriterija za odabir radnih mikroorganizama (Binod $i$ sur., 2013). Glavne karakteristike radnih mikroorganizama za proizvodnju etanola su velik prinos etanola, velika produktivnost i tolerancija na velike koncentracije etanola. Također, mikroorganizam bi trebao imati sposobnost konverzije više različitih šećera, kao i toleranciju prema inhibitorima u lignoceluloznim hidrolizatima. Uz to bi trebao tolerirati niske pH-vrijednosti i velike temperature kako bi se smanjio rizik od kontaminacije. Veća temperatura fermentacije smanjuje mogućnost pojave mezofilnih kontaminanata. Na taj način se smanjuje potreba za sterilizacijom i proces postaje ekonomičniji. Tijekom postupaka selekcije testiraju se učinkovitost i prinos velikog broja izoliranih sojeva te postojanost njihovih svojstava. Za proizvodnju etanola iz lignoceluloznih hidrolizata mogu se koristiti razni mikroorganizmi - kvasci, neke bakterije, te više vrsta filamentoznih funga. Kvasci se među ostalim mikroorganizmima za proizvodnju etanola ističu po svojstvima kao što su velika specifična brzina rasta, učinkovita represija glukozom, dobra proizvodnja etanola i tolerancija na okolišni stres (npr. velike koncentracije etanola). lako može fermentirati isključivo heksoze, Saccharomyces cerevisiae je industrijski najznačajnija vrsta kvasaca. Za ekonomičnu i održivu konverziju lignoceluloze u etanol traže se mikroorganizmi koji mogu fermentirati i druge šećere poput ksiloze, manoze, arabinoze ili galaktoze. To je moguće primjenom kvasaca kao što su Schizosaccharomyces pombe, Kluyveromyces lactis te vrste rodova Candida i Pichia (Binod i sur., 2013).

U tekstu koji slijedi bit će navedene karakteristike najvažnijih rodova i vrsta kvasaca koji se mogu koristiti za proizvodnju etanola iz lignoceluloznih sirovina. Primjeri istraživanja proizvodnje etanola iz lignoceluloznih sirovina s pomoću opisanih kvasaca navedeni su u Tablici 1.

Tablica 1. Primjeri istraživanja kvasaca za proizvodnju bioetanola

Table 1. Examples of yeast research for bioethanol production

\begin{tabular}{|c|c|c|c|}
\hline $\begin{array}{c}\text { Radni } \\
\text { mikroorganizam }\end{array}$ & $\begin{array}{c}\text { Sirovina / hranjiva } \\
\text { podloga }{ }^{a}\end{array}$ & Pokazatelji učinkovitosti ${ }^{b}$ & Referenca \\
\hline $\begin{array}{l}\text { Saccharomyces } \\
\text { cerevisiae }\end{array}$ & $\begin{array}{l}\text { Ječmena slama } \\
\text { (predobrada razrijeđenom } \\
\text { sumpornom kiselinom, a } \\
\text { potom parom) }\end{array}$ & $\begin{array}{l}Y_{P}=15,5-22,4 \mathrm{~g} / \mathrm{L} \\
E=80-82 \%\end{array}$ & Linde i sur. (2007) \\
\hline $\begin{array}{l}\text { Termotolerantni } \\
\text { flokulentni kvasac S. } \\
\text { cerevisiae }\end{array}$ & $\begin{array}{l}\text { Pšenična slama } \\
\text { (hidrotermalna } \\
\text { predobrada) }\end{array}$ & $Y_{P}=14,84 \mathrm{~g} / \mathrm{L}\left(\operatorname{pri} 45^{\circ} \mathrm{C}\right)$ & Ruiz i sur. (2012) \\
\hline $\begin{array}{l}\text { Saccharomyces } \\
\text { cerevisiae }\end{array}$ & $\begin{array}{l}\text { Lignocelulozni otpad } \\
\text { dobiven nakon cijeđenja } \\
\text { ploda Indijskog oraha } \\
\text { (Anacardium occidentale) }\end{array}$ & $\begin{array}{l}Y_{P}=5,6 \mathrm{~g} / \mathrm{L} \\
\operatorname{Pr}=1,41 \mathrm{~g} / \mathrm{Lh}\end{array}$ & $\begin{array}{l}\text { Rodrigues i sur. } \\
\text { (2011) }\end{array}$ \\
\hline $\begin{array}{l}\text { Saccharomyces } \\
\text { cerevisiae }\end{array}$ & $\begin{array}{l}\text { Otpadne kore naranče } \\
\text { (obrada parnom } \\
\text { eksplozijom) }\end{array}$ & $\begin{array}{l}Y_{p}=39,60 \mathrm{~g} / \mathrm{L} \text { dobiveno } \\
\text { variranjem više parametara }\end{array}$ & Wilkins i sur. (2007) \\
\hline $\begin{array}{l}\text { Saccharomyces } \\
\text { cerevisiae }\end{array}$ & $\begin{array}{l}\text { Ostaci od proizvodnje } \\
\text { kave }\end{array}$ & $\begin{array}{l}Y_{P}=15,3 \mathrm{~g} / \mathrm{L} \\
\mathrm{E}=87,2 \%\end{array}$ & Choi i sur. (2012) \\
\hline
\end{tabular}




\section{Radni mikroorganizam}

\section{Sirovina / hranjiva podloga ${ }^{a}$}

Pokazatelji učinkovitosti ${ }^{b}$

Referenca

\begin{tabular}{|c|c|c|c|}
\hline $\begin{array}{l}\text { Candida shehatae } \\
\text { ATY839 }\end{array}$ & $\begin{array}{l}\text { Alkalno obrađena rižina } \\
\text { slama }\end{array}$ & $\begin{array}{l}E=71,6 \% \text { nakon } 24 \mathrm{~h} \text {. } \\
\text { Superioran u odnosu } \\
\text { na druge sojeve } \\
\text { (Saccharomyces cerevisiae } \\
\text { NBRC 0224, Scheffersomyces } \\
\text { stipitis NBRC } 10063 \text { i C. } \\
\text { shehatae ATCC } 22984 \text { ) } \\
\text { s kojima je uspoređen } \\
\text { tijekom preliminarnih } \\
\text { istraživanja. }\end{array}$ & $\begin{array}{l}\text { Tanimura i sur. } \\
\text { (2012) }\end{array}$ \\
\hline $\begin{array}{l}\text { Candida glabrata } \\
\text { Cgrd1 koja nema } \\
\text { respiratorni lanac }\end{array}$ & $\begin{array}{l}\text { Celuloza uz primjenu } \\
\text { simultane saharifikacije i } \\
\text { fermentacije (SSF) }\end{array}$ & $\begin{array}{l}\text { Postiže veću proizvodnju } \\
\text { etanola od sojeva C. } \\
\text { glabrata NFRI3164 i } S \text {. } \\
\text { cerevisiae korištenih za } \\
\text { usporedbu }\end{array}$ & $\begin{array}{l}\text { Watanabe isur. } \\
\text { (2010) }\end{array}$ \\
\hline Candida shehatae & $\begin{array}{l}\text { Kemijski definirana } \\
\text { podloga (ksiloza } 90 \mathrm{~g} / \mathrm{L} \text { ) }\end{array}$ & $\begin{array}{l}Y_{p}=37 \mathrm{~g} / \mathrm{L} \mathrm{u} \\
\text { dvostupanjskom procesu, } \\
Y_{p}=38 \mathrm{~g} / \mathrm{L} \text { u šaržnom } \\
\text { uzgoju }\end{array}$ & $\begin{array}{l}\text { Alexander i sur. } \\
\text { (1988) }\end{array}$ \\
\hline $\begin{array}{l}\text { Kluveromyces } \\
\text { marxianus SUB 80-S }\end{array}$ & $20 \mathrm{~g} / \mathrm{L}$ ksiloze & $\begin{array}{l}Y_{P}=5,6 \mathrm{~g} / \mathrm{L} \\
Y_{P /}=0,28 \mathrm{~g} \text { etanola } / \mathrm{g} \\
\text { ksiloze }\end{array}$ & $\begin{array}{l}\text { Margaritis i Bajpai } \\
\text { (1982) }\end{array}$ \\
\hline $\begin{array}{l}\text { Kluveromyces } \\
\text { marxianus CECT } 10875\end{array}$ & $\begin{array}{l}\text { Biomasa topole i } \\
\text { eukaliptusa }\end{array}$ & $\begin{array}{l}Y_{P}=16-19 \mathrm{~g} / \mathrm{L} \\
E=50-72 \%\end{array}$ & $\begin{array}{l}\text { Ballesteros i sur. } \\
(2004)\end{array}$ \\
\hline $\begin{array}{l}\text { Termostabilni } \\
\text { soj Kluveromyces } \\
\text { marxianus CECT } 10875\end{array}$ & $\begin{array}{l}\text { Pšenična slama obrađena } \\
\text { parnom eksplozijom, } \\
\text { a potom simultana } \\
\text { saharifikacija i fermentacija }\end{array}$ & $\begin{array}{l}Y_{p}=36,2 \mathrm{~g} / \mathrm{L} \text { u šaržnom } \\
\text { postupku s prihranjivanjem } \\
(20 \% \text { više nego u šaržnom } \\
\text { postupku) }\end{array}$ & $\begin{array}{l}\text { Tomas-Pejo i sur. } \\
\text { (2009) }\end{array}$ \\
\hline $\begin{array}{l}\text { Kluveromyces } \\
\text { marxianus CECT } 10875\end{array}$ & $\begin{array}{l}\text { Ječmena slama obrađena } \\
\text { parnom eksplozijom }\end{array}$ & $\begin{array}{l}Y_{p}=22 \mathrm{~g} / \mathrm{L} \text { nakon } 72 \mathrm{~h}(E= \\
67,4 \% \text { izračunato na suhu } \\
\text { tvar) }\end{array}$ & $\begin{array}{l}\text { García-Aparicio } i \\
\text { sur. (2011) }\end{array}$ \\
\hline $\begin{array}{l}\text { Kluveromyces } \\
\text { marxianus IMB3 }\end{array}$ & $\begin{array}{l}\text { Ukrasno proso (eng. } \\
\text { switchgrass, lat. Panicum } \\
\text { virgatum) podvrgnuto } \\
\text { hidrotermolizi }\end{array}$ & $Y_{P}=22,5 \mathrm{~g} / \mathrm{L}, E=86 \%$ & Pessani i sur. (2011) \\
\hline $\begin{array}{l}\text { Kluveromyces } \\
\text { marxianus CECT } 10875\end{array}$ & $\begin{array}{l}\text { Topola (Populus nigra) } \\
\text { ekspandirana parom ili } \\
\text { obrađena vrućom vodom }\end{array}$ & $\begin{array}{l}Y_{p}=20 \mathrm{~g} / \mathrm{L} \text { nakon } 72 \mathrm{~h} \\
\text { (iskorištenje } 60 \% \text { u odnosu } \\
\text { na teorijsko). Bolji je prinos } \\
\text { uz prethodnu ekspanziju } \\
\text { parom pri } 240^{\circ} \mathrm{C} \text { ). }\end{array}$ & Negro i sur. (2003) \\
\hline Pichia stipitis & $\begin{array}{l}\text { Hidrolizati šumske vrste } \\
\text { Prosopis juliflora }\end{array}$ & $Y_{P}=7,13 \mathrm{~g} / \mathrm{L}$ & Gupta i sur. (2009) \\
\hline Pichia stipitis 3498 & $\begin{array}{l}\text { Biljka Lantana camara } \\
\text { hidrolizirana razrijeđenom } \\
\text { kiselinom i detoksicirana }\end{array}$ & $\begin{array}{l}\text { Nakon } 24 \text { sata } Y_{P}=5,16 \mathrm{~g} / \mathrm{L}, \\
Y_{P / \mathrm{S}}=0,33 \mathrm{~g} / \mathrm{g} \\
P r=0,23 \mathrm{~g} / \mathrm{L} / \mathrm{h}\end{array}$ & Kuhad i sur. (2010) \\
\hline $\begin{array}{l}\text { Pichia stipitis NCIM- } \\
3497\end{array}$ & $\begin{array}{l}\text { Kiselinski hidrolizat } \\
\text { vodenog zumbula } \\
\text { (eng. water hyacinth), } \\
\text { detoksiciran }\end{array}$ & $\begin{array}{l}Y_{P / s}=0,425 \mathrm{~g} \text { etanola } / \mathrm{g} \\
\text { lignoceluloze }\end{array}$ & Binod i sur. (2013) \\
\hline
\end{tabular}




\begin{tabular}{|c|c|c|c|}
\hline $\begin{array}{c}\text { Radni } \\
\text { mikroorganizam }\end{array}$ & $\begin{array}{c}\text { Sirovina / hranjiva } \\
\text { podloga }{ }^{a}\end{array}$ & Pokazatelji učinkovitosti b & Referenca \\
\hline $\begin{array}{l}\text { Pichia stipitis DSM } \\
3651\end{array}$ & $\begin{array}{l}\text { Hidrolizat bagase (ostatak } \\
\text { nakon prerade šećerne } \\
\text { trske), uz dodatak } \\
\text { kvaščevog ekstrakta, } \\
\text { sladnog ekstrakta i } \\
\text { peptona }\end{array}$ & $\begin{array}{l}Y_{p / s}=0,30 \mathrm{~g} / \mathrm{g} \text { (detoksicirani } \\
\text { hidrolizat) } \\
Y_{p / s}=0,20 \mathrm{~g} / \mathrm{g} \text { (bez } \\
\text { detoksikacije) }\end{array}$ & Canilha isur. (2010) \\
\hline $\begin{array}{l}\text { Pichia stipitis NRRL } \\
\text { Y-7124 }\end{array}$ & $\begin{array}{l}\text { Kiselinski hidrolizat rižine } \\
\text { slame }\end{array}$ & $\operatorname{Pr}=0,39 \mathrm{~g} / \mathrm{Lh}, E=72,5 \%$ & Silva i sur. (2010) \\
\hline Pichia stipitis & $\begin{array}{l}\text { Hidrolizat drveta Acer } \\
\text { saccharum (hrv. šećerni } \\
\text { javor) }\end{array}$ & $\begin{array}{l}Y_{P}=29,7 \mathrm{~g} / \mathrm{L} \text { uz vrlo nisku } \\
\text { koncentraciju kisika i } \\
\text { miješanje } 150 \text { okretaja u } \\
\text { minuti. }\end{array}$ & Shupe i Liu (2012) \\
\hline Pichia stipitis CBS 5776 & $\begin{array}{l}\text { Kukuruzovina obrađena } \\
\text { parnom eksplozijom, bez } \\
\text { detoksikacije }\end{array}$ & $\begin{array}{l}Y_{P}=\text { preko } 94,68 \mathrm{~g} / \mathrm{L}, E= \\
\text { preko } 80 \%\end{array}$ & Yong i sur. (2012) \\
\hline
\end{tabular}

a Prikazana istraživanja provedena su na lignoceluloznim sirovinama nakon prethodno provedene predobrade ili u kemijski definiranim podlogama koje oponašaju kemijski sastav lignoceluloznih hidrolizata.

${ }^{b} Y_{p}-$ prinos etanola $(g / L)$

$Y_{p / s}-$ koeficijent konverzije supstrata u produkt ( $g$ etanola / $g$ supstrata)

$Y_{p / S}($ teor) - teorijski koeficijent konverzije supstrata u produkt ( $g$ etanola / $g$ supstrata)

$E$-iskorištenje (\%); $E=Y_{P / S} / Y_{P / S}$ (teor)

$\mathrm{Pr}$ - produktivnost (g etanola/Lh)

${ }^{a}$ The studies have been carried out on lignocellulosic raw materials after pretreatment or in

chemically defined substrates mimicking the chemical composition of lignocellulosic hydrolysates

${ }^{b} Y_{p}$-ethanol yield $(\mathrm{g} / \mathrm{L})$

$Y_{P / S}-$ yield of substrate to product conversion ( $g$ ethanol / $g$ substrate)

$Y_{p / s}($ theor) - theoretical yield of substrate to product conversion (g ethanol / $g$ substrate)

$E$-efficiency (\%); $E=Y_{P / S} / Y_{P / S}$ (theor)

$\mathrm{Pr}$ - productivity (g ethanol/Lh)

\section{Kvasci koji se istražuju i koriste za proizvodnju bioetanola iz hidroliza- ta lignoceluloznih sirovina}

\section{Kvasci roda Saccharomyces}

Rod Saccharomyces je od velike važnosti u tradicionalnim i suvremenim biotehnološkim procesima. Vrste koje pripadaju ovom rodu mogu fermentirati velik broj supstrata, uključujući glukozu, fruktozu, galaktozu, maltozu, saharozu, ksilulozu, dekstrin, rafinozu i škrob. Metodama genetičkog inženjerstva neki su sojevi modificirani tako da metaboliziraju lignocelulozne šećere kao što su ksiloza i arabinoza (Dufour i sur., 2011).

Gotovo sva svjetska proizvodnja etanola provodi se s kvascem Saccharomyces cerevisiae (Binod $i$ sur., 2013). Stanice te vrste vrlo su otporne na inhibitore i produkte fermentacije te fermentiraju šećere pri niskim pH-vrijednostima, što smanjuje rizik kontaminacije. Stoga se kvasac S. cerevisiae pored tradicionalne primjene za dizanje tijesta pri izradi kruha i za proizvodnju fermentiranih alkoholnih pića, također koristi i za industrijsku proizvodnju specijalnih kemikalija i bioetanola (Weber $i$ sur., 2010; Dufour $i$ sur., 2011). S. cerevisiae 
pokazuje veliku toleranciju na etanol u tekućoj kulturi i veliku sposobnost proizvodnje etanola (Morais i sur., 1996; Dufour i sur., 2011). Obzirom da ne može fermentirati pentoze poput ksiloze i arabinoze (Olofsson i sur., 2008; Weber i sur., 2010), primijenjeni su različiti pristupi kako bi se metabolički putevi za korištenje ovih pentoza integrirali u kvasac S. cerevisiae (van Maris i sur., 2007; Weber i sur., 2010), koji je među najbolje istraženim mikroorganizmima te postoji velik broj metoda za njegovu genetičku modifikaciju (van Maris i sur., 2007; Weber $i$ sur., 2010). Primjeri proizvodnje etanola iz lignoceluloznih sirovina pomoću kvasca S. cerevisiae navedeni su u Tablici 1.

\section{Kvasci roda Candida}

Rod Candida uključuje oko 200 poznatih vrsta kvasaca, od kojih su mnoge važne za proizvodnju biogoriva. Ovaj rod kvasaca poznat je po vrsti Candida albicans, koja je patogena za ljude i uzrokuje kandidijazu i gljivične infekcije (Dufour i sur., 2011). Nekoliko vrsta, uključujući C. lusitaniae, C. shehatae i C. tropicalis može koristiti ksilozu. Vrste ovog roda također koriste celobiozu, manozu, saharozu i fruktozu. Termotolerantni kvasac Candi-da acidothermophilum kao glavni proizvod fermentacije glukoze daje etanol, do $80 \%$ stehiometrijskog prinosa (Kadam i Schmidt, 1997; Dufour i sur., 2011). Većina kvasaca roda Candida može rasti aerobno na ksilozi, ali samo nekolicina može fermentirati ksilozu i time proizvesti etanol (Binod, 2013). Jedan od primjera je kvasac C. tropicalis, koji može fermentirati ksilozu u uvjetima limitacije kisikom uz povećane koncentracije polietilen glikola.

\section{Kvasci roda Kluyveromyces}

Rod kvasaca Kluyveromyces ima dobru sposobnost fermentacije, a pripadaju mu vrste koje mogu rasti na galaktozi, laktozi, inulinu, fruktozi i ksilozi (Dufour i sur., 2011). Kao i kod roda Candida, neke od vrsta iz roda Kluyveromyces su poznati oportunistički patogeni kod imunokompromitiranih bolesnika, što otežava postizanje GRAS statusa koji ima S. cerevisiae. Među vrstama kvasaca iz roda Kluyveromyces, od velikog interesa za biotehnološku primjenu je soj Kluyveromyces marxianus (Fonseca i sur., 2008).

Prednosti kvasca K. marxianus koje ga čine zanimljivim za konverziju biomase u etanol su zadovoljavajući prinos etanola pri fermentaciji ksiloze, termotolerancija koja omogućuje rast pri temperaturama do $52{ }^{\circ} \mathrm{C}$ (Banat $i$ sur., 1992) i mogućnost fermentacije pri temperaturama iznad $40{ }^{\circ} \mathrm{C}$. S industrijskog gledišta to bi moglo smanjiti troškove hlađenja i rizik od kontaminacije, pojednostaviti uklanjanje etanola te predstavljati prednost kod simultane enzimske saharifikacije i fermentacije, jer takvi uvjeti rasta i fermentacije odgovaraju optimalnim temperaturama za celulolitičke enzime. Veće temperature fermentacije povećavaju produktivnost postrojenja. Obzirom na velik stupanj varijabilnosti unutar vrste K. marxianus, izoliran je i istraživan niz različitih sojeva ovog kvasca koji se razlikuju po svojoj sposobnosti rasta i fermentacije na različitim supstratima (npr. Suryawati i sur., 2008; Wilkins i sur., 2008; Kumar i sur., 2009; Weber i sur., 2010). Unatoč obećavajućim rezultatima fermentacije glukoze pri temperaturama iznad $40{ }^{\circ} \mathrm{C}$, uz prinos koji je iznosio do $98 \%$ od teorijskog (Banat i sur., 1992), problem je to što se ksiloza u velikoj mjeri prevodi u ksilitol, a ne $u$ etanol, a to se nepovoljno odražava na ekonomičnost procesa proizvodnje etanola iz lignoceluloznih sirovina. Uz to, iako postoji mogućnost povećanja temperature pri fermentaciji, prisutan je i negativan utjecaj temperature na prinos etanola, preživljavanje stanica i toleranciju na etanol. 


\section{Kvasci roda Pichia (Scheffersomyces)}

Noviji naziv roda Pichia je Scheffersomyces, ali se još uvijek u velikom dijelu literature koristi stari naziv. Ovom rodu pripada i kvasac Pichia stipitis (Scheffersomyces stipitis), koji je zanimljiv prvenstveno zbog toga što je jedan od rijetkih kvasaca koji mogu fermentirati ksilozu. Smatra se da za industrijsku proizvodnju etanola iz lignoceluloznih sirovina najviše obećava upravo ovaj kvasac (Agbogbo i sur., 2006; Weber i sur., 2010; Dufour i sur., 2011). Kvasac $P$. stipitis također može fermentirati glukozu, galaktozu i celobiozu (Weber $i$ sur., 2010), te također posjeduje različite celulaze i hemicelulaze (Jeffries $i$ sur., 2007). To može biti od koristi pri simultanoj saharifikaciji i fermentaciji iako je optimalna temperatura rasta ovog kvasca oko $30^{\circ} \mathrm{C}$.

Kvasac Pichia stipitis pokazuje veliku proizvodnju etanola iz ksiloze, pri čemu neki sojevi proizvode gotovo $6 \mathrm{~g} / \mathrm{L}$ etanola. To je $67 \%$ od teorijskog prinosa, koji iznosi $9 \mathrm{~g} / \mathrm{L}$ etanola nakon 10 dana u primijenjenoj hranjivoj podlozi sa 2 \% ksiloze (Toivola $i$ sur., 1984; Dufour i sur., 2011). Optimiranjem koncentracije kisika, u kontinuiranom uzgoju je postignut maksimalni prinos od 0,48 g/g (gram etanola po gramu ksiloze) i specifična produktivnost 0,20 g/L/h (Skoog i Hahn-Hägerdal, 1990; Dufour i sur. 2011). Osim toga, pokazalo se da je za proizvodnju etanola u podlozi koja sadrži $150 \mathrm{~g} / \mathrm{L}$ ksiloze pomoću kvasca $P$. stipitis optimalna pH-vrijednost 4-7 te optimalna temperatura $34^{\circ} \mathrm{C}$, čime se postiže maksimalni prinos od $57 \mathrm{~g} / \mathrm{L}$ (Slininger i sur., 1990; Dufour i sur., 2011).

Brzine potrošnje šećera u kvascu $P$. stipitis su manje nego u kvascu S. cerevisiae, što je djelomično povezano s transportom šećera (Ligthelm i sur., 1988; Agbogbo i Coward-Kelly, 2008; Weber i sur., 2010). Da bi se postigli veći prinos etanola i veća tolerancija ovog kvasca prema inhibitorima i etanolu, pokušava se optimirati sastav hranjive podloge ili primijeniti genetičke modifikacije (Bajwa i sur., 2009; Bajwa i sur., 2010; Slininger i sur., 2009). U optimiranom definiranom mediju koji sadrži $150 \mathrm{~g} / \mathrm{L}$ ksiloze moguće je postići prinos $61 \mathrm{~g} / \mathrm{L}$ etanola $\left(Y_{p}\right)$, uz koeficijent konverzije supstrata u produkt $\left(Y_{P / S}\right)$ koji iznosi 0,41 gram etanola/gramu ksiloze (Slininger i sur., 2006).

Za industrijsku primjenu potrebno je odabrati prikladan izvor dušika jer je to preduvjet za proizvodnju etanola u fazi procesa kada stanice više ne rastu. Nadalje, kvasac $P$. stipitis pokazuje optimalnu proizvodnju etanola samo pri mikroaerofilnim uvjetima, dok aerobno ne proizvodi etanol čak i uz suvišak šećera. Produktivnost kvasca $P$. stipitis istraživana je $u$ nizu različitih hidrolizata, pri čemu su uočeni koeficijenti konverzije supstrata u produkt $\left(Y_{p / S}\right)$ bili u rasponu 0,31 - 0,48 g etanola/g utrošenog šećera (Weber $i$ sur., 2010).

\section{Kvasci roda Schizosaccharomyces}

Schizosaccharomyces je rod fisijskih kvasaca, koji mogu fermentirati ksilozu u etanol pri mikroaerofilnim ili kisikom limitiranim uvjetima. Lastick i sur. (1990) su dokazali da simultana fermentacija i izomerizacija ksiloze (eng. simultaneous fermentation and isomerization of xylose, SFIX) omogućuje potpunu fermentaciju ksiloze u jednom koraku. SFIX omogućuje značajno poboljšanje fermentacije ksiloze u etanol obzirom da je brža i bolje tolerira veće koncentracije ksiloze i etanola (Binod i sur., 2013).

\section{Kvasci roda Pachysolen}

Saharan i Sharma (2010) istraživali su kvasac Pachysolen tannophilus i dokazali da trehaloza ima zaštitnu ulogu u stanjima oksidativnog stresa uzrokovanog etanolom. $U$ jednom drugom istraživanju (Binod i sur., 2013) u kojem su primijenjene različite metode uzgoja 
kvasca Pachysolen tannophilus (šaržni uzgoj, šaržni uzgoj s prihranjivanjem i kontinuirani uzgoj) na različitim supstratima u aerobnim, anaerobnim i mikroaerobnim uvjetima $u$ bioreaktoru s mješalom uočeno je da se pri anaerobnim uvjetima dobiva relativno mala količina kvaščeve biomase i etanola. Najviše etanola proizvedeno je u mikroaerobnim uvjetima (Binod i sur., 2013).

\section{Zaključci}

Lignocelulozna biomasa je pogodna obnovljiva sirovina za proizvodnju bioetanola. Pored tehnoloških izazova, nameće se i potreba odabira prikladnog mikroorganizma za fermentaciju lignoceluloznih hidrolizata, koji sadrže heksoze i pentoze, ali i inhibitore fermentacije. Zahvaljujući dobrim proizvodnim svojstvima i toleranciji na stres, kvasci zauzimaju posebno važno mjesto među mikroorganizmima koji proizvode bioetanol. Uz kvasac Saccharomyces cerevisiae, istraživani su i kvasci Schizosaccharomyces pombe, Kluyveromyces lactis te vrste koje pripadaju rodovima Candida, Pichia (Scheffersomyces) i Pachysolen. Pored kvasaca iz roda Saccharomyces, koji se najčešće koriste za komercijalno dobivanje bioetanola, smatra se da najveći potencijal za buduću industrijsku primjenu imaju kvasci iz roda Pichia (Scheffersomyces). Provođenjem selekcije, adaptacije ili genetičke modifikacije nastoji se postići ekonomična proizvodnja etanola fermentacijom lignoceluloznih hidrolizata.

\section{Literatura}

Agbogbo, F.K., Coward-Kelly, G., Torry-Smith, M., Wenger, K.S. (2006). Fermentation of glucose/xylose mixtures using Pichia stipitis. Process Biochemistry, 41, 2333-2336.

Agbogbo, F.K., Coward-Kelly, G. (2008). Cellulosic ethanol production using the naturally occurring xylose-fermenting yeast, Pichia stipitis. Biotechnology Letters, 30, 515-1524.

Alexander, M.A., Chapman, T.W., Jeffries, T.W. (1988). Continuous xylose fermentation by Candida shehatae in a twostage reactor. Applied Biochemistry and Biotechnology, 17, 221-229.

Alonso Bocchini Martins D., Ferreira Alves do Prado H., Simões Ribeiro Leite R., Ferreira H., de Souza Moretti M. M., da Silva R., Gomes E. (2011). Agroindustrial wastes as substrates for microbial enzymes production and source of sugar for bioethanol production. U: Integrated waste management - Volume II, Mr. Sunil Kumar (Ed.), InTech, pp. 319-360. https://cdn.intechopen.com/pdfs-wm/18493.pdf

Alriksson, B. (2006). Ethanol from lignocellulose: Alkali detoxification of dilute-acid spruce hydrolysates. Dissertation for the degree of Doctor of Science in Technology, Karlstad University Studies.

Anwar Z., Gulfraz M., Irshad M. (2014) Agro-industrial lignocellulosic biomass a key to unlock the future bio-energy: A brief review. Journal of Radiation Research and Applied Sciences 7 163-173.

Bajwa, P.K., Shireen, T., D'Aoust, F., Pinel, D., Martin, V.J.J., Trevors, J.T., Lee, H. (2009). Mutants of the pentosefermenting yeast Pichia stipitis with improved tolerance to inhibitors in hardwood spent sulfite liquor. Biotechnology and Bioengineering, 104, 892-900.

Bajwa, P.K., Pinel, D., Martin, V.J.J., Trevors, J.T., Lee, H. (2010). Strain improvement of the pentose-fermenting yeast Pichia stipitis by genome shuffling. Journal of Microbiological Methods, 81, 179-186.

Ballesteros, M., Oliva, J.M., Negro, M.J., Manzanares, P., Ballesteros, I. (2004). Ethanol from lignocellulosic materials by a simultaneous saccharification and fermentation process (SFS) with Kluyveromyces marxianus CECT 10875. Process Biochemistry 39, 1843-1848.

Banat, I.M., Nigam, P., Marchant, R. (1992). Isolation of thermotolerant, fermentative yeasts growing at $52^{\circ} \mathrm{C}$ and producing ethanol at $45^{\circ} \mathrm{C}$ and $50^{\circ} \mathrm{C}$. World Journal of Microbiology and Biotechnology, 8, 259-263.

Binod, P., Sindhu, R., Pandey A. (2013). The alcohol fermentation step: The most common ethanologenic microorganisms among yeasts, bacteria and filamentous fungi. U: Lignocellulose conversion - enzymatic and microbial tools for bioethanol production, Faraco, V., (ur.), Springer-Verlag Berlin Heidelberg, London/ New York, str. 131-149.

Canilha, L., Carvalho, W., Felipe, M.das G., Silva, J.B., Giulietti, M. (2010). Ethanol production from sugarcane bagasse hydrolysate using Pichia stipitis. Applied Biochemistry and Biotechnology, 161, 84-92.

Chlopek, Z. (2007). Ecological aspects of using bioethanol fuel to power combustion engines. Maintenance and Reliability, 3, 65-69

Choi, S., Wi, S.G., Kim, S.-B., Bae, H.-J. (2012). Conversion of coffee residue waste into bioethanol with using popping pretreatment. Bioresource Technology, 125, 132-137.

Chen H., Liu J., Chang X., Chen D., Xue Y., Liu P., Lin H., Han S. (2017) A review on the pretreatment of lignocellulose for high-value chemicals. Fuel Processing Technology 160(1), 196-206.

Chiaramonti D., Prussi M., Ferrero S., Oriani L., Ottonello P., Torre P., Cherchi F. (2012) Review of pretreatment processes for lignocellulosic ethanol production, and development of an innovative method. Biomass and bioenergy 46 25-35.

Dufour, N., Swana J., Rao R.P. (2011). Fermentation organisms for 5- and 6-carbon sugars. U: Plant Biomass Conversion, Hood E.E., Nelson, P., Powell, R., (ur.), John Wiley \& Sons Inc., Chichester, str. 157-197. 
Fonseca, G.G., Heinzle, E., Wittmann, C., Gombert, A.K. (2008). The yeast Kluyveromyces marxianus and its biotechnological potential. Applied Microbiology and Biotechnology, 79, 339-354.

García-Aparicio, M.P., Oliva, J.M., Manzanares, P., Ballesteros, M., Ballesteros, I., González, A., Negro, M.J. (2011). Second-generation ethanol production from steam exploded barley straw by Kluyveromyces marxianus CECT 10875. Fuel, 90, 1624-1630.

Gupta, R., Sharma, K.K., Kuhad, R.C. (2009). Separate hydrolysis and fermentation (SHF) of Prosopis juliflora, woody substrate for the production of cellulosic ethanol by Saccharomyces cerevisiae and Pichia stipitis NCIM 3498. Bioresource Technology, 100, 1214-1220.

loelovich, M. (2014). Correlation analysis of enzymatic digestibility of plant biomass, Biomass Conversion and Biorefinery, 4 (3), 269-275, http://www.academia.edu/9097146/Correlation_Analysis_of_Enzymatic_Digestibility_of_ Plant_Biomass. (accessed: 31. 5. 2016.)

Hilgert M. N; Kaldstrom J; Rinaldi M; Schüth R., Ferdi: Katalytisches Vermahlen: Ein neuer Zugang für LignocelluloseBioraffinerien, Max-Planck-Institut für Kohlenforschung, 2013.

https://www.mpg.de/6698004/JB_20132.pdf

Isikgor F. H., Becer C. R. (2015) Lignocellulosic biomass: a sustainable platform for the production of bio-based chemicals and polymers. Polymer Chemistry, 6, 4497-4559.

Janušić, V., Ćurić, D., Krička, T., Voća, N., Matin, A. (2008). Predtretmani u proizvodnji bioetanola iz lignocelulozne biomase. Poljoprivreda, 14 (1), 53-58.

Jeffries, T.W., Grigoriev, I.V., Grimwood, J., Laplaza, J.M., Aerts, A., Salamov, A., Schmutz, J., Lindquist, E., Dehal, P., Shapiro, H., Jin, Y.-S., Passoth, V., Richardson, P.M. (2007). Genome sequence of the lignocellulose-bioconverting and xylose-fermenting yeast Pichia stipitis. Nature Biotechnology, 25, 319-326.

Kadam, K.L., Schmidt, S.L. (1997). Evaluation of Candida acidothermophilum in ethanol production from lignocellulosic biomass. Applied Microbiology and Biotechnology, 48 (6), 709-713.

Kuhad, R.C., Gupta, R., Khasa, Y.P., Singh, A. (2010). Bioethanol production from Lantana camara (red sage): pretreatment, saccharification and fermentation. Bioresource Technology, 101, 8348-8354.

Kumar, P., Barrett, D. M., Delwiche, M. J., Stroeve, P. (2009a) Methods for pretreatment of lignocellulosic biomass for efficient hydrolysis and biofuel production. Industrial and Egineering Chemistry Research 48 (8), 3713-3729.

Kumar, S., Singh, S.P., Mishra, I.M., Adhikari, D.K. (2009b). Ethanol and xylitol production from glucose and xylose at high temperature by Kluyveromyces sp. IIPE453. Journal of Industrial Microbiology and Biotechnology, 36, 1483-1489.

Kumar AK, Sharma S. (2017) Recent updates on different methods of pretreatment of lignocellulosic feedstocks: a review. Bioresources and Bioprocessing 4(1), 7. doi: 10.1186/s40643-017-0137-9. Epub 2017 Jan 18.

Lastick, S.M., Mohagheghi, A., Tucker, M.P., Grohmann, K. (1990). Simultaneous fermentation and isomerization of xylose to ethanol at high xylose concentrations. Applied Biochemistry and Biotechnology, 24 (25), 431-439.

Linde M, Galbe G, Zacchi G (2007). Simultaneous saccharification and fermentation of steam pretreated barley straw at low enzyme loadings and low yeast concentration. Enzyme and Microbial Technology, 40, 1100-1107.

Margaritis, A., Bajpai, P. (1982). Direct fermentation of D-xylose to ethanol by Kluyveromyces marxianus strains. Applied and Environmental Microbiology, 44 (5), 1039-1041.

Mood S. H., Golfeshan A.H., Tabatabaei M., Jouzani G. S., Najafi G. H., Gholami M., Ardjmand M. (2013) Lignocellulosic biomass to bioethanol, a comprehensive review with a focus on pretreatment. Renewable and Sustainable Energy Reviews 27, 77-93.

Morais, P.B., Rosa, C.A., Linardi, V.R., Carazza, F., Nonato, E.A. (1996). Production of fuel alcohol by Saccharomyces strains from tropical habitats. Biotechnology Letters, 18 (11), 1351-1356.

Mosier N., Wyman C., Dale B., Elander R., Lee Y.Y., Holtzapple M., Ladisch M. (2005) Features of promising technologies for pretreatment of lignocellulosic biomass. Bioresource Technology, 96, 673-686.

Mussatto, S.I., Roberto, I.C. (2003). Alternatives for detoxification of diluted-acid lignocellulosic hydrolyzates for use in fermentative processes: A review. Bioresource Technology, 93, 1-10.

Mussatto SI, Teixeira JA (2010) Lignocellulose as raw material in fermentation processes. In: Méndez-Vilas A.(ur.) Current research, technology and education topics in applied microbiology and microbial biotechnology, vol 2. Formatex Research Center, Badajoz, Spain, pp 897-907.

Negro, M.J., Manzanares, P., Ballesteros, I., Oliva, J.M., Cabañas, A., Ballesteros, M. (2003). Hydrothermal pretreatment conditions to enhance ethanol production from poplar biomass. Applied Biochemistry and Biotechnology, 105 (1-3), 87100.

Olofsson, K., Bertilsson, M., Liden, G. (2008). A short review on SSF-an interesting process option for ethanol production from lignocellulosic feedstocks. Biotechnology for Biofuels, 1, 1-14.

Palmqvist E., Hahn-Hägerdal B. (2000a). Fermentation of lignocellulosic hydrolysates I: inhibition and detoxification. Bioresource Technology 74, 17-24.

Palmqvist E., Hahn-Hägerdal B. (2000b) Fermentation of lignocellulosic hydrolysates II: inhibitors and mechanisms of inhibition. Bioresource Technology, 74, 25-33.

Pérez J., Munoz-Dorado J., de la Rubia T., Martínez J. (2002) Biodegradation and biological treatments of cellulose, hemicellulose and lignin: an overview. International Microbiology, 5: 53-63.

Pessani, N.K., Atiyeh, H.K., Wilkins, M.R., Bellmer, D.D., Banat, I.M. (2011). Simultaneous saccharification and fermentation of Kanlow switchgrass by thermotolerant Kluyveromyces marxianus IMB3: the effect of enzyme loading, temperature and higher solid loadings. Bioresource Technology, 102, 10618-10624.

Putro JN, Soetaredjo FE, Lin SY, Ju YH, Ismadji S (2016) Pretreatment and conversion of lignocellulose biomass into valuable chemicals. RSC Advances 6 (52), 46834-46852.

Rodrigues, T.H.S., Rocha, M.V.P., de Macedo, G.R., Goncalves, L.R.B. (2011). Ethanol production from cashew apple bagasse: improvement of enzymatic hydrolysis by microwave-assisted alkali pretreatment. Applied Biochemistry and Biotechnology, 164, 929-943.

Ruiz, H.A., Silva, D.P., Ruzene, D.S., Lima, L.F., Vicente, A.A., Teixeira, J.A. (2012). Bioethanol production from hydrothermal pretreated wheat straw by a flocculating Saccharomyces cerevisiae strain-effect of process conditions. Fuel, 95, 528-536.

Saharan, R.K., Sharma, S.C. (2010). Correlation studies of trehalose with oxidative stress in ethanol stressed yeast Pachysolen tannophilus. Current Research Journal of Biological Sciences, 2 (5), 300-305.

Salvachua, D., Prieto, A., Lopez-Abelairas, M., Lu-Chau, T., Martinez, A.T., Martinez, M.J. (2011). Fungal pretreatment: An 
alternative in second-generation ethanol from wheat straw, Bioresource Technology, 102, 7500-7506.

Shupe, A.M., Liu, S. (2012). Effect of agitation rate on ethanol production from sugar maple hemicellulosic hydrolysate by Pichia stipitis. Applied Biochemistry and Biotechnology, 168, 29-36.

Silva, J.P.A., Mussatto, S.I., Roberto, I.C. (2010). The influence of initial xylose concentration, agitation and aeration on ethanol production by Pichia stipitis from rice straw hemicellulosic hydrolysate. Applied Biochemistry and Biotechnology, $162,1306-1315$.

Skoog, K., Hahn-Hägerdal, B. (1990). Effect of oxygenation on xylose fermentation by Pichia stipitis. Applied and Environmental Microbiology, 56(11), 3389-3394.

Slininger, P.J., Bothast, R.J., Ladisch, M.R., Okos, M.R. (1990). Optimum pH and temperature conditions for xylose fermentation by Pichia stipitis. Biotechnology and Bioengineering, 35, 727-731.

Slininger, P.J., Dien, B.S., Gorsich, S.W., Liu, Z.L. (2006). Nitrogen source and mineral optimization enhance D-xylose conversion to ethanol by the yeast Pichia stipitis NRRL Y-7124. Applied Microbiology and Biotechnology, 72, 1285-1296.

Slininger, P.J., Gorsich, S.W., Liu, Z.L. (2009). Culture nutrition and physiology impact the inhibitor tolerance of the yeast Pichia stipitis NRRL Y-7124. Biotechnology and Bioengineering, 102 (3), 778-790.

Sluiter, J. B., Ruiz, R. O., Scarlata, C. J., Sluiter, A. D., Templeton, D. W. (2010). Compositional analysis of lignocellulosic feedstocks, 1. Review and description of methods, Journal of Agricultural and Food Chemistry, 58, 9043-9053.

Srivastava N., Rawat R., Singh Oberoi H., Ramteke P.W. (2015). A review on fuel ethanol production from lignocellulosic biomass. International Journal of Green Energy, 12 (9): 949-960.

Sun, Y., Cheng, J. (2002). Hydrolysis of lignocellulosic materials for ethanol production: A review, Bioresource Technology., 83, 1-11.

Suryawati, L., Wilkins, M.R., Bellmer, D.D., Huhnke, R.L., Maness, N.O., Banat, I.M. (2008). Simultaneous saccharification and fermentation of Kanlow switchgrass pretreated by hydrothermolysis using Kluyveromyces marxianus IMB4. Biotechnology and Bioengineering, 101 (5), 894-902.

Taherzadeh, M.J., Karimi, K. (2007). Acid-based hydrolysis processes for ethanol from lignocellulosic materials: A review. BioResources, 2 (3), 472-499.

Taherzadeh, M.J., Karimi, K. (2008). Pretreatment of lignocellulosic wastes to improve ethanol and biogas production: A review. International Journal of Molecular Sciences, 9 (9), 1621-1651.

Tanimura, A., Nakamura, T., Watanabe, I., Ogawa, J., Shima, J. (2012). Isolation of a novel strain of Candida shehatae for ethanol production at elevated temperature. SpringerPlus, 1 (27), 1-7.

Toivola, A., Yarrow, D., van den Bosch, E., van Dijken, J.P., Scheffers, W.A. (1984). Alcoholic fermentation of D-xylose by yeasts. Applied and Environmental Microbiology, 47 (6), 1221-1223.

Tomás-Pejó, E., Oliva, J.M., González, A., Ballesteros, I., Ballesteros, M. (2009). Bioethanol production from wheat straw by the thermotolerant yeast Kluyveromyces marxianus CECT 10875 in a simultaneous saccharification and fermentation fed-batch process. Fuel, 88, 2142-2147.

van Maris, A.J.A., Winkler, A.A., Kuyper, M., de Laat, W.T.A.M., van Dijken, J.P., Pronk, J.T. (2007). Development of efficient xylose fermentation in Saccharomyces cerevisiae: xylose isomerase as a key component. Advances in Biochemical Engineering/Biotechnology, 108, 179-204.

Watanabe, I., Nakamura, T., Shima, J. (2010). Strategy for simultaneous saccharification and fermentation using a respiratory-deficient mutant of Candida glabrata for bioethanol production. Journal of Bioscience and Bioengineering, 110 (2), 176-179.

Weber, C., Farwick, A., Benisch, F., Brat, D., Dietz, H., Subtil, T., Boles, E. (2010). Trends and challenges in the microbial production of lignocellulosic bioalcohol fuels. Applied Microbiology and Biotechnology, 87, 1303-1315.

Wilkins, M.R., Widmer, W.W., Grohmann, K. (2007). Simultaneous saccharification and fermentation of citrus peel waste by Saccharomyces cerevisiae to produce ethanol. Process Biochemistry, 42, 1614-1619.

Wilkins, M.R., Mueller, M., Eichling, S., Banat, I.M. (2008). Fermentation of xylose by the thermotolerant yeast strains Kluyveromyces marxianus IMB2, IMB4 and IMB5 under anaerobic conditions. Process Biochemistry, 43, 346-350.

Yong, Q., Li, X., Yuan, Y., Lai, C., Zhang, N., Chu, Q., Xu, Y., Yu, S. (2012). An improved process of ethanol production from hemicellulose: bioconversion of undetoxified hemicellulosic hydrolyzate from steam-exploded corn stover with a domesticated Pichia stipitis. Applied biochemistry and biotechnology, 167, 2330-2340.

Zhang B, Shahbazi A (2011) Recent developments in pretreatment technologies for production of lignocellulosic biofuels. Journal of Petroleum and Environmental Biotechnology 2:108. https://www.omicsonline.org/recentdevelopments-in-pretreatment-technologies-for-production-of-lignocellulosic-biofuels-2157-7463.1000108.pdf

\section{Abstract}

Huge amounts of lignocellulosic waste, consisting mainly of cellulose, hemicellulose and lignin, are generated through forestry, agriculture and food industry. Given the available amount of these cheap and renewable raw materials in the Republic of Croatia, it is important to consider the possibility of their conversion into ethanol and other biotechnological products. Lignocellulosic hydrolysates are complex mixtures of hexoses, pentoses and other compounds, some of which may act as fermentation inhibitors. This paper reviews yeast strains that are used and/or studied for ethanol production by fermentation of lignocellulosic hydrolyzates.

Keywords: bioethanol, lignocellulose, microorganisms, hexoses, pentoses, inhibitors 